Image Capture, Processing and Analysis of Solar Cells for Engineering Education

Dr. Michael G Mauk P.E., Drexel University

Dr. Richard Chiou, Drexel University (Eng. \& Eng. Tech.) 


\title{
Image Capture, Processing and Analysis of Solar Cells for Engineering Education
}

\begin{abstract}
We explore the use of several image capture, processing, and analysis techniques and methodologies to study various aspects of solar cells including their materials, device operation, defects, variability, and reliability. Laboratory projects using low-cost fluorescent cameras, visible and near-IR cameras, and laser scanning are used to characterize the grain structure, defects, surface roughness, reflectivity, and photovoltaic effects in common solar cell materials (e.g., monocrystalline and multicrystalline silicon wafers, thin film solar cells, commercial silicon solar cells, and photovoltaic modules. Captured images can be imported into MATLAB or other widely-available image processing software for analysis and interpretation. Topical laboratory modules and projects can teach across engineering disciplines including materials science, optics, quality control, semiconductor devices, and renewable energy.

\section{Introduction and Background}

If present trends hold, the world may well be on the verge of the "Solar Age", where photovoltaics will make a substantial (> 20\%) contribution to our total electrical energy needs. Photovoltaic materials, devices, and systems should therefore be prominent in engineering education. In addition, solar cells are very informative specimens for teaching image capture, processing, and analysis as means for studying materials science, semiconductor devices, optics, thin-film technology, manufacturing automation, machine vision, quality assurance, and statistical process control. For example, imaging a solar cell with visible and infrared cameras can reveal its grain structure (grain size and texture), crystallographic defects, surface reflectivity and roughness, surface contamination, and manufacturing flaws (e.g., broken grid lines or chips). As a further example, laser scanning with image mapping provides spatial resolution of performance-limiting features and effects for solar cell diagnostics. Solar cells are made in a variety of materials and configurations, and generally exhibit a wide range of optical, electrical, and thermal phenomena including in addition to the photovoltaic effect, photoluminescence, electroluminescence, photoconductivity, and light trapping. The operation of a solar cell, as well as many phenomena revealed by imaging, are sensitive to material quality, and thus solar cells are good "probes" of material properties. High resolution visible and infrared (thermal) cameras are now available at low cost. Solar cells are cheap and readily available. Powerful image processing software comes with MATLAB ${ }^{\mathrm{TM}}$ or freeware (Image ${ }^{\mathrm{TM}}$ ). Most of the experiments can be done on a desktop or lab bench. Thus, these experiments and projects make only modest demands on school resources. Here we describe and discuss solar cell imaging as accessible, highly instructive, easy-to-implement case studies for teaching and integrating a variety of increasingly important engineering and science disciplines.
\end{abstract}




\section{Investigation of Solar Cell Microstructure Using Image Analysis}

Solar cells, especially those made in polycrystalline materials, as well as multicrystalline silicon wafers and sheets, have an easily revealed and prominent microstructure. Grain boundaries and grains (typically a few millimeters to centimeters in size) can be imaged with a low magnification (10 to 100x) CCD camera. Further, defects, anomalies in coatings, contamination, and surface roughness can be studied by image processing. Figure 1 shows some samples of the variety of textures commonly encountered with silicon solar cells.

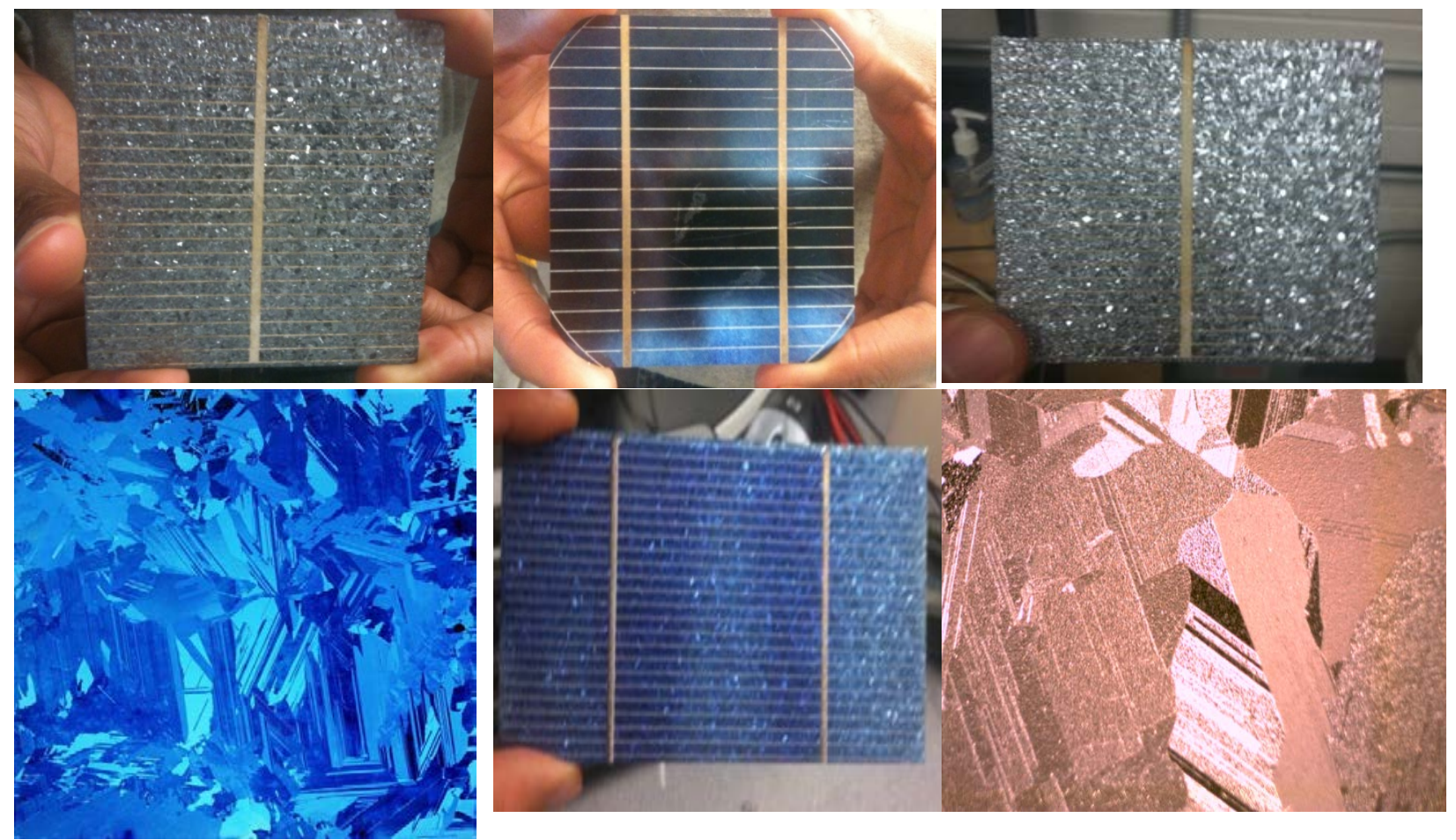

Figure 1: Typical silicon solar cell and silicon wafer textures.

These images are sensitive to the angle and color of illumination, which can be optim-ized to enhance contrast and detect flaws. Students designed and constructed an imaging station with a CCD camera and a fixture for illumination allowing multicolor illumination by red, green, and blue LEDs, and various angles of illumination (Figure 2). 

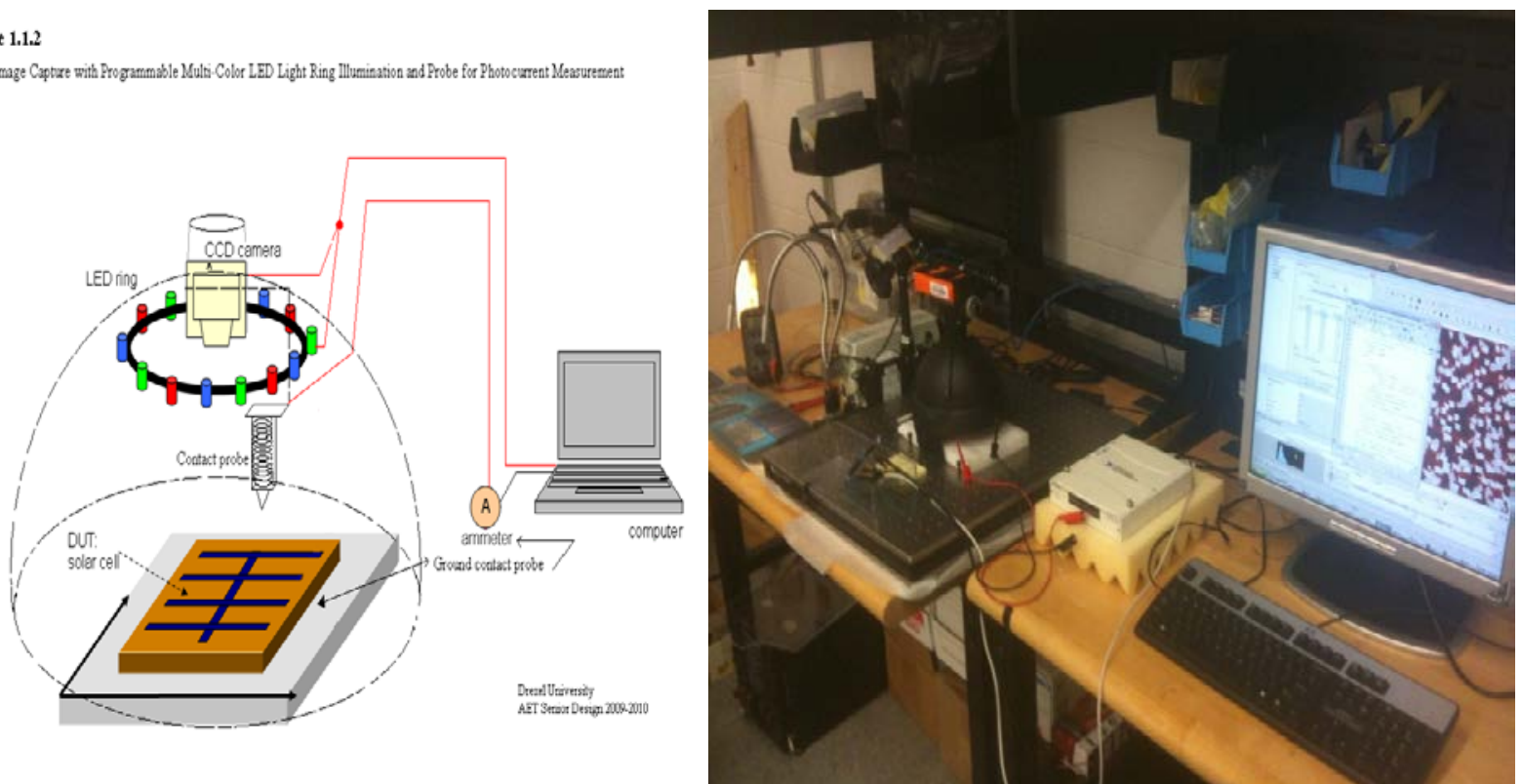

Figure 2: Imaging station for multicolor, variable angle of illumination imaging of solar cells.

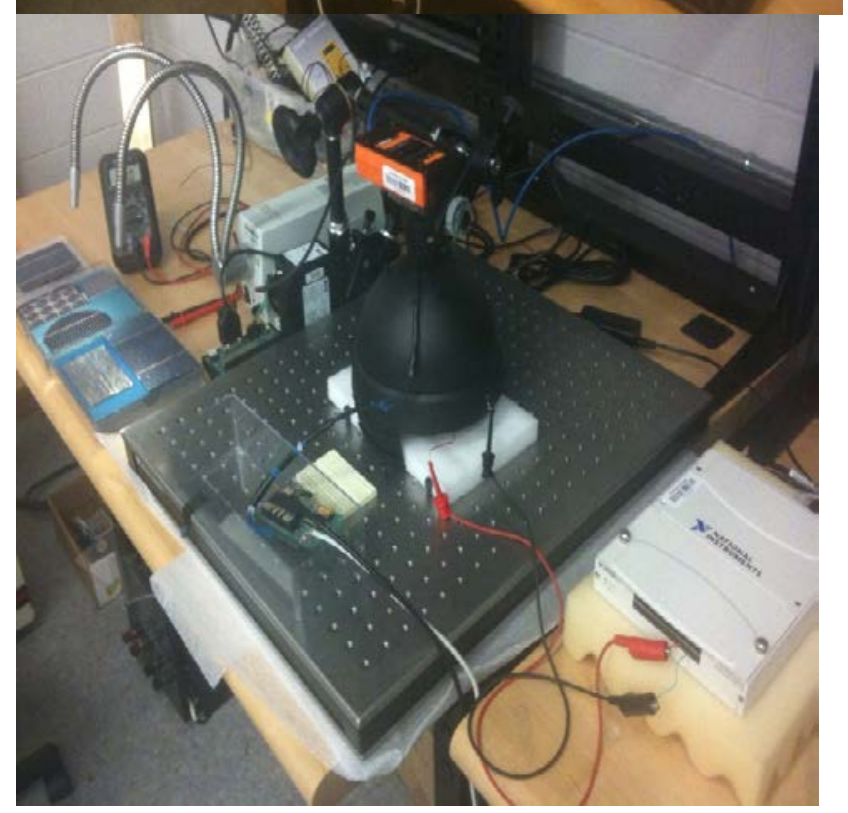

From these images, students are able to perform image analysis (using MATLAB ${ }^{\circledR}$ or ImageJ) to estimate average grain size, texture (preferred orientation of grains), surface roughness, reflectivity, and detect flaws in solar cells such as scratches, microcracks, broken grid lines, and blemishes in anti-reflection coatings. Many of these features are important in quality control in solar cell production.

Figures 3 through 10 provide examples of analysis of solar cells and solar cell wafers relating to grain size characterization, defects, and surface roughness using images of solar cells captured by CCD cameras. 
Direct Illumination of Polycrystalline Solar Cell under MAX power
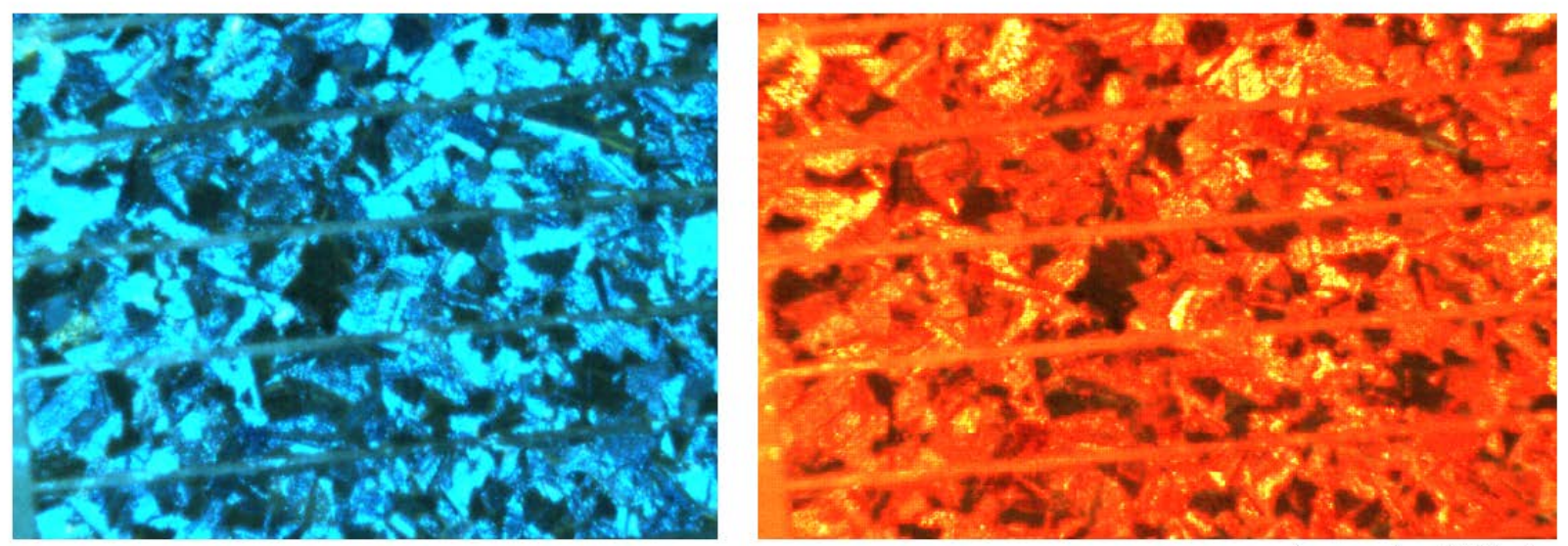

Images courtesy of Will Peeples

Figure 3: Grains of polycrystalline silicon reflect light differently. Variable contrast of screen-printed metal grid lines (four shown in figure) makes inspection of grid line integrity challenging.

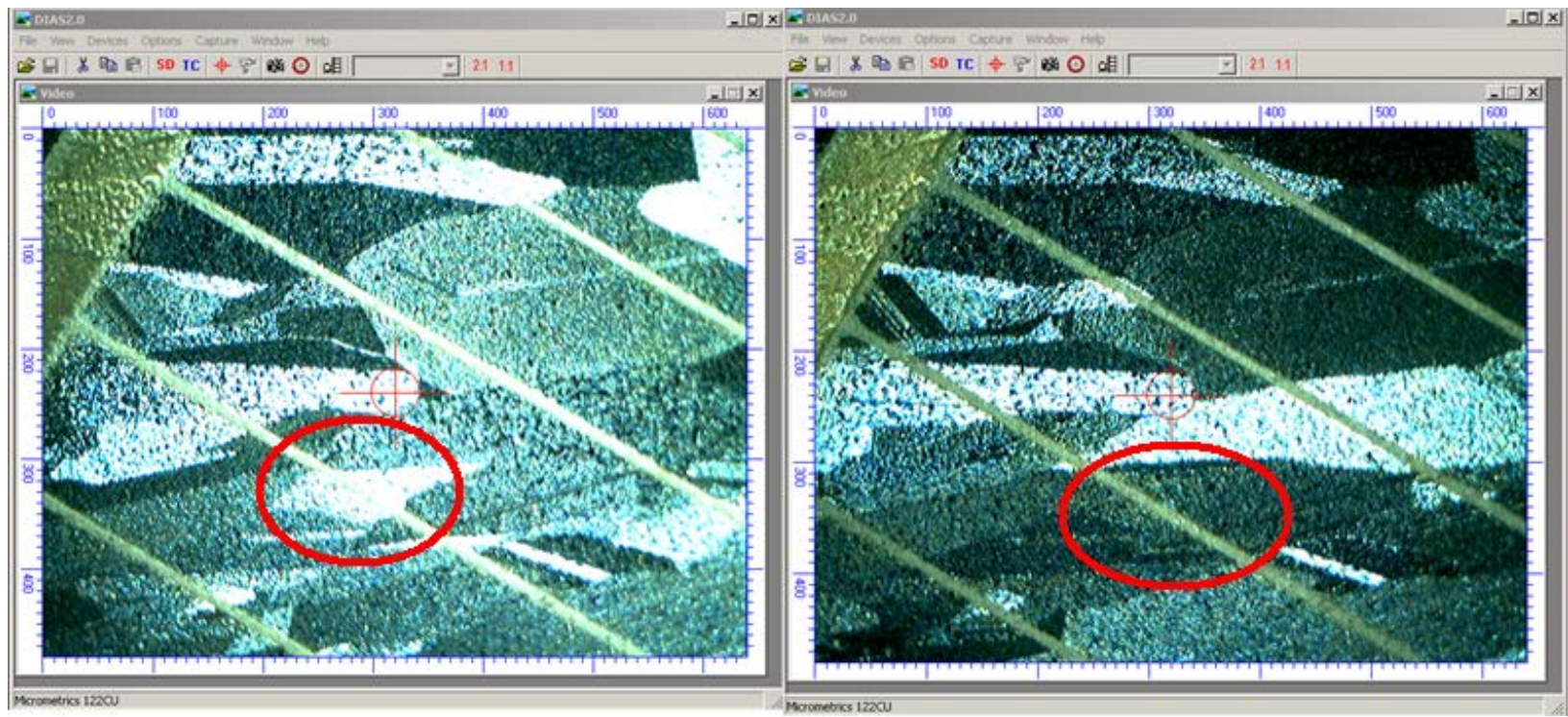

Figure 4: By varying angle and intensity of illumination the continuity of grid lines can be more accurately assessed. 

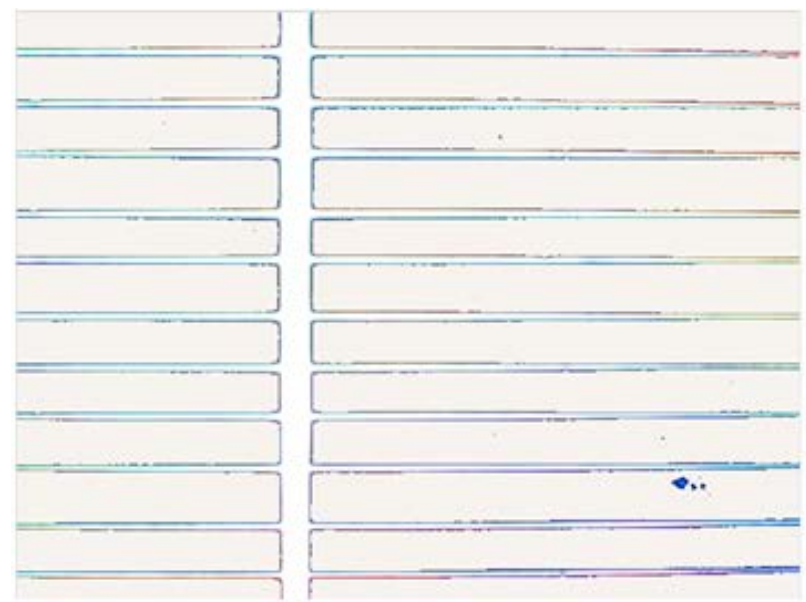

Cell 13
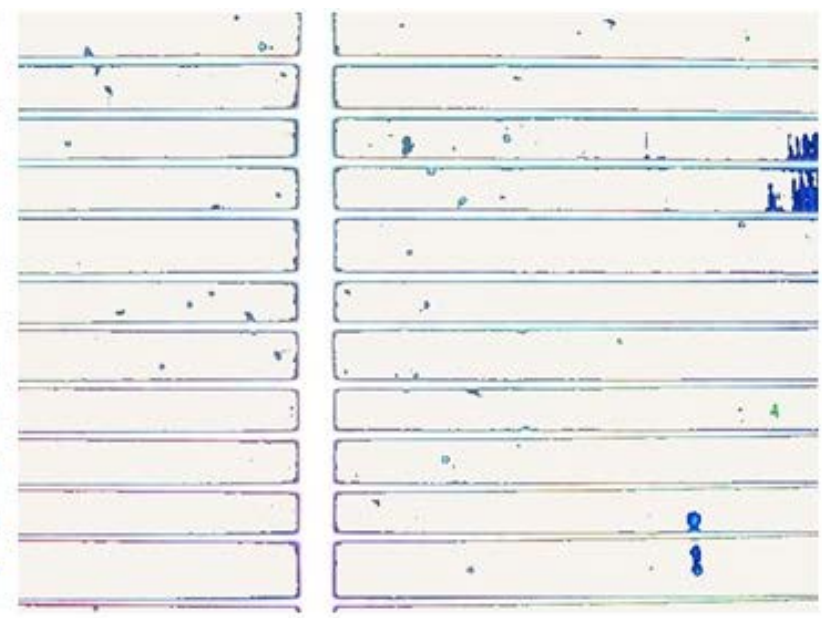

Cell 8

Figure 5: Solar cells can also be imaged for inspection of particulate contamination and pinhole-type defects by varying contrast, light intensity, illumination light color, and angle of incidence.

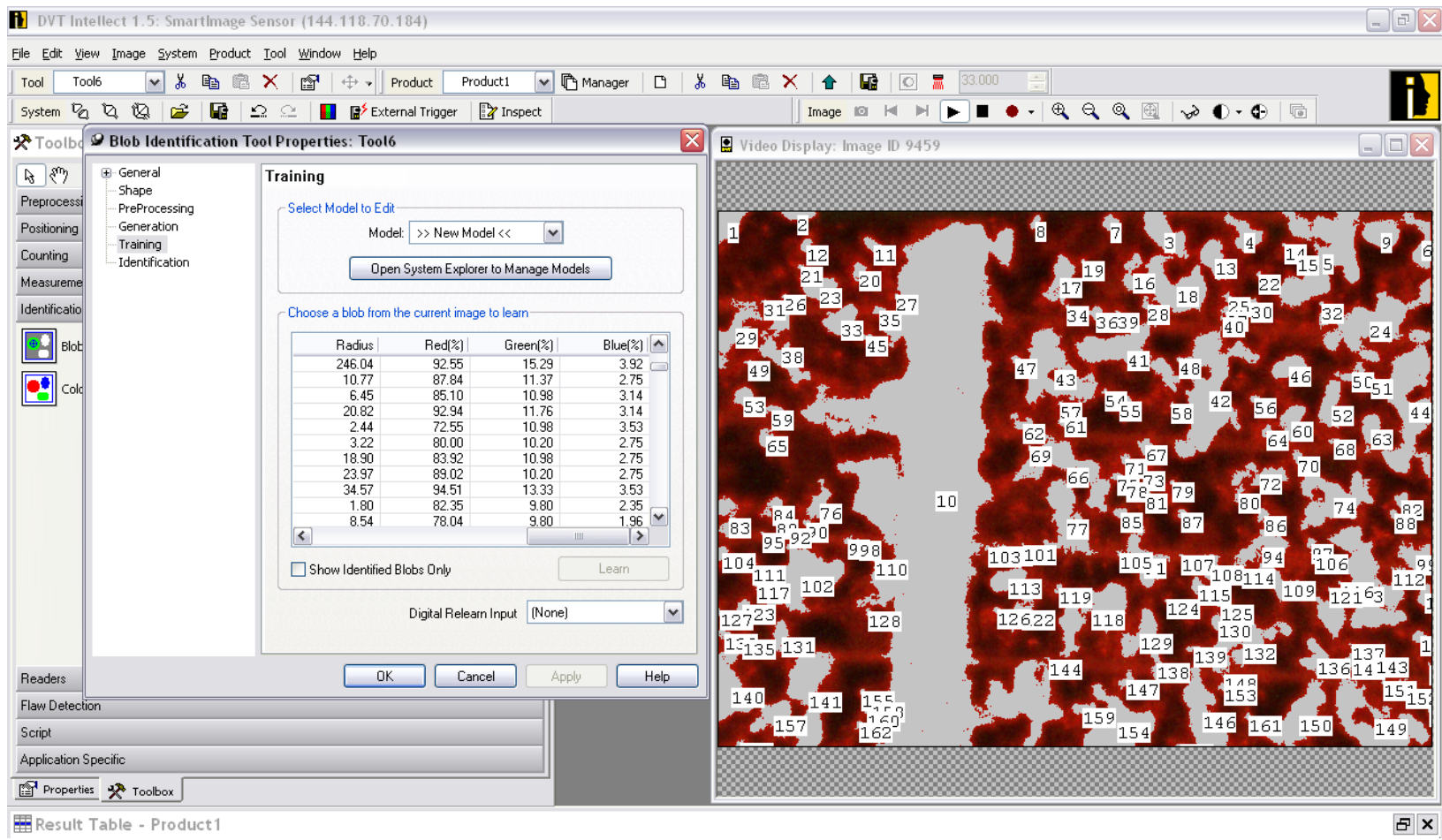

Figure 6: Characterization of grain size distribution can also be performed by various image processing utilities available in MATLAB and ImageJ software. 


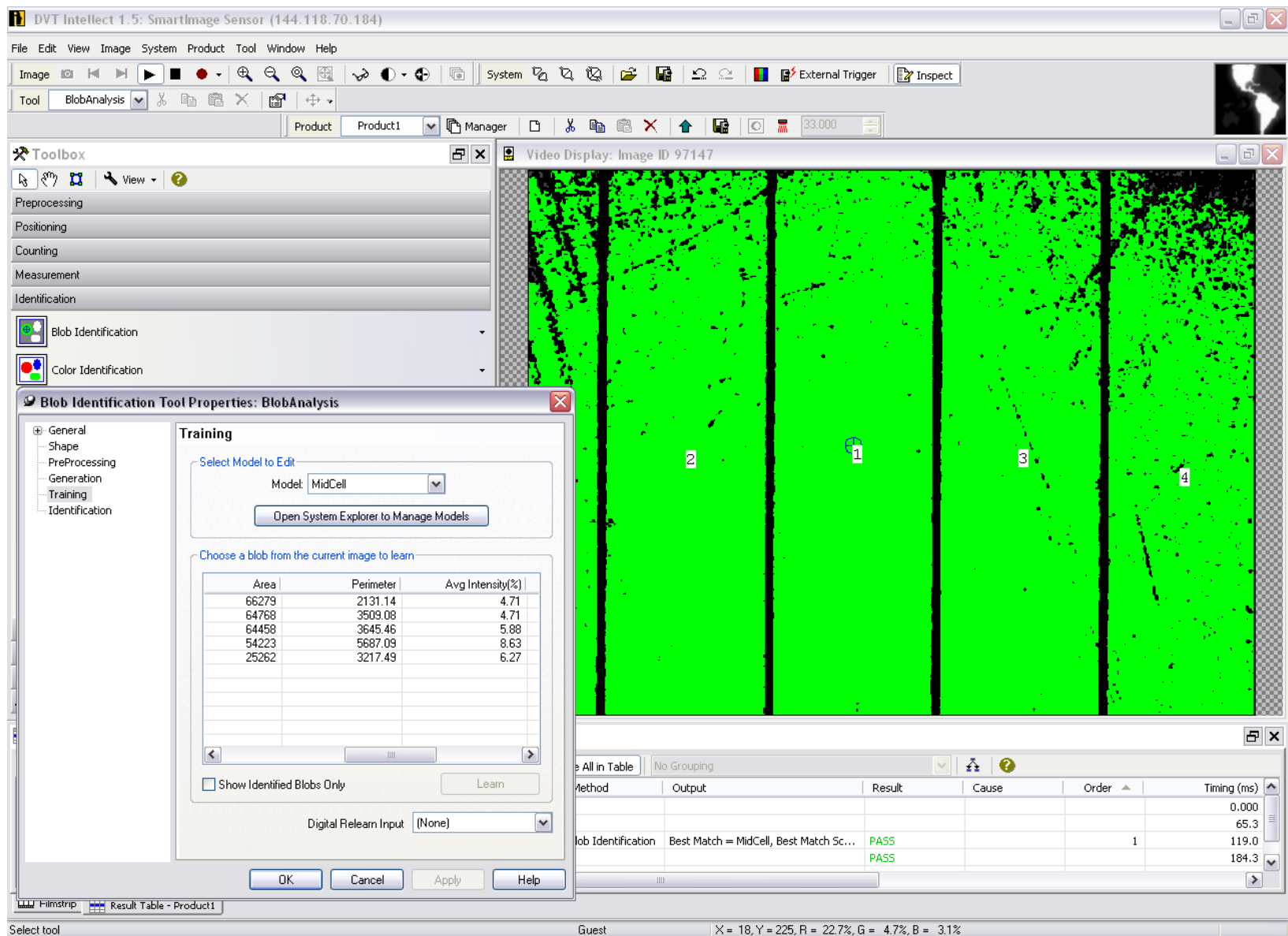

Figure 7: Many statistics of features revealed by imaging can be used as metrics for quality control and correlation with solar cell performance.
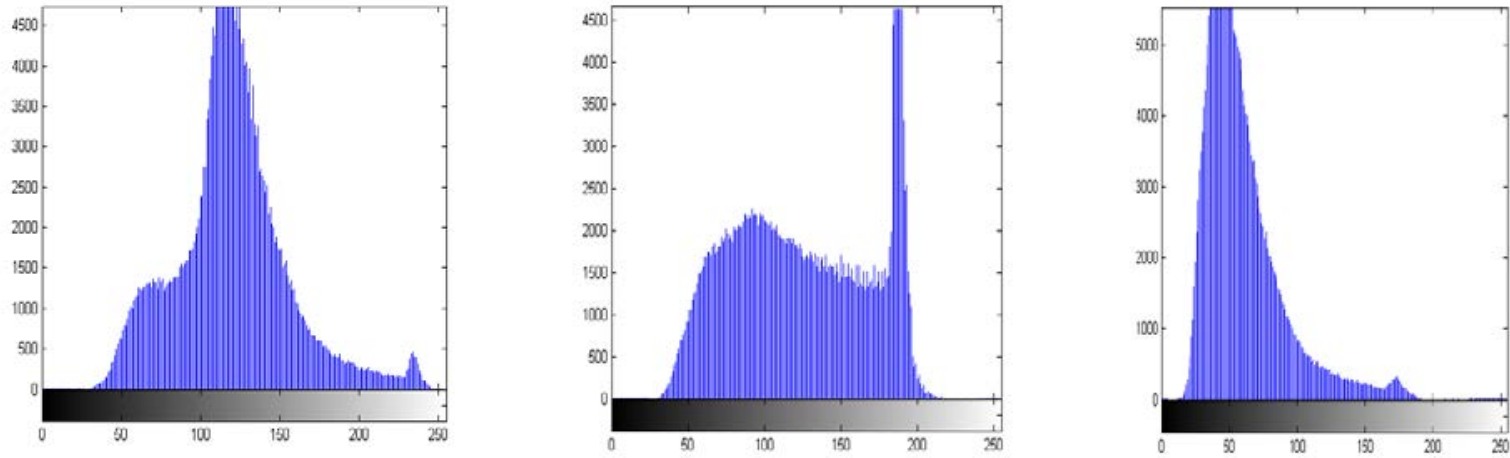

Figure 8: Histograms of pixel intensity distribution is a simple analysis for analysis of solar cells. 


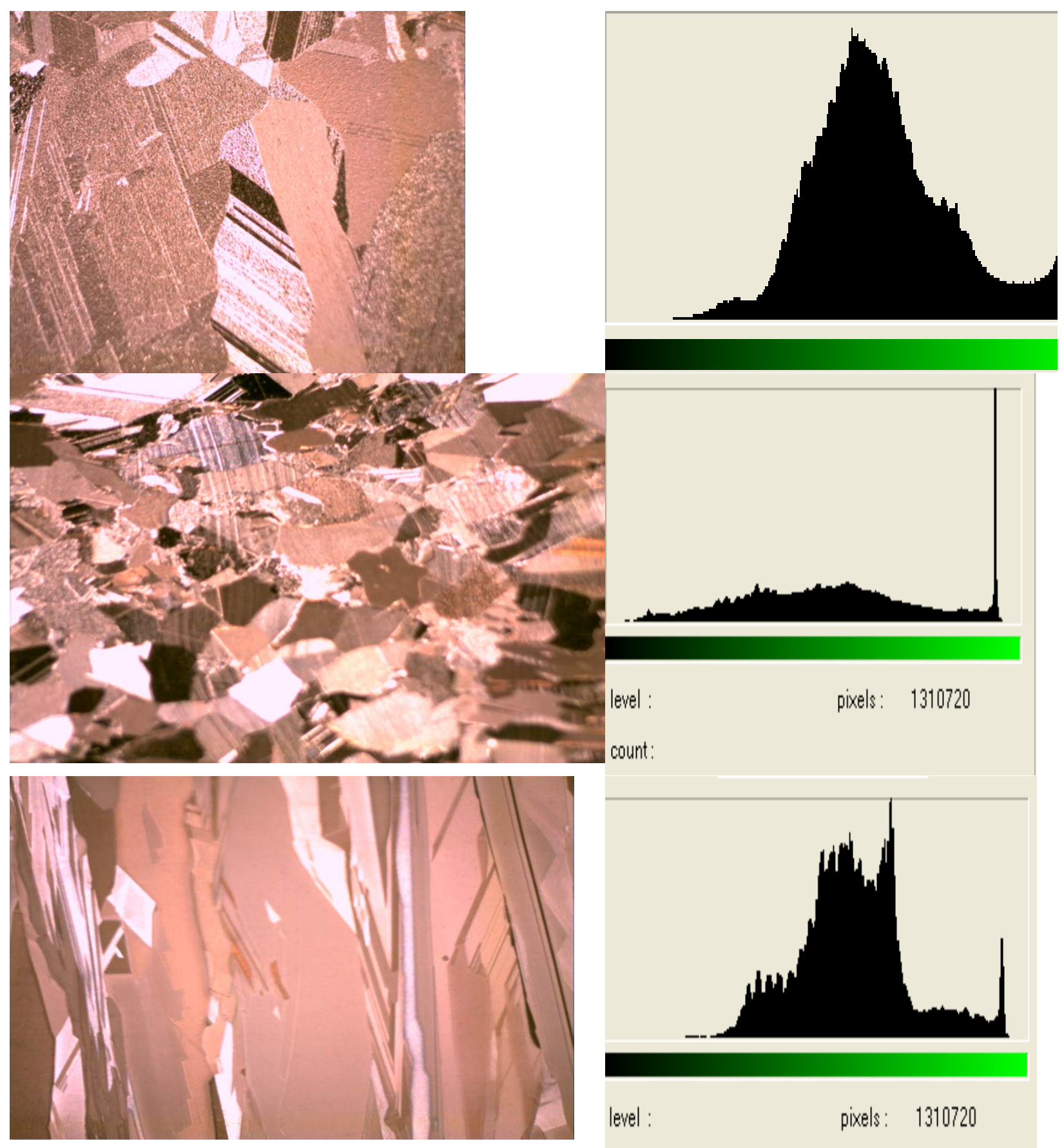

Figure 9: Histograms of pixel intensity distribution correlated with various grain textures of multicrystalline silicon samples. 

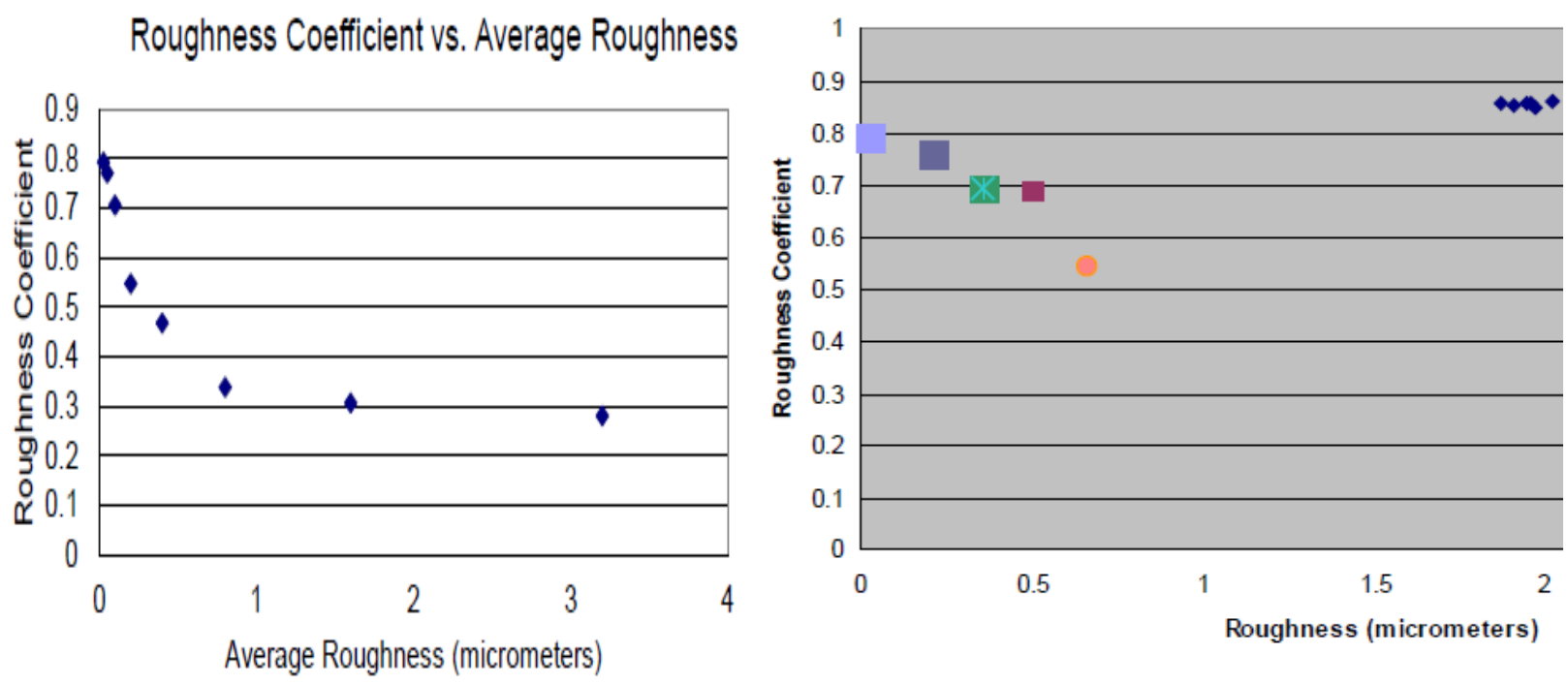

Figure 10: Relative variance or standard deviation of pixel intensity was correlated to surface roughness measured by surface profiling. Thus, image analysis in some instances can provide a useful non-contact method of surface roughness estimation.

Students then adapted the stationery image capture station to a conveyer built system, where solar cells or wafers were conveyed under the camera to detect flaws (Figures 11 and 12). A robot arm with a suction cup can pick up solar cells where image analysis indicates some anomaly or flaw. Solar cells can be sorted into bins based on criteria indicated by image analysis "on the fly".

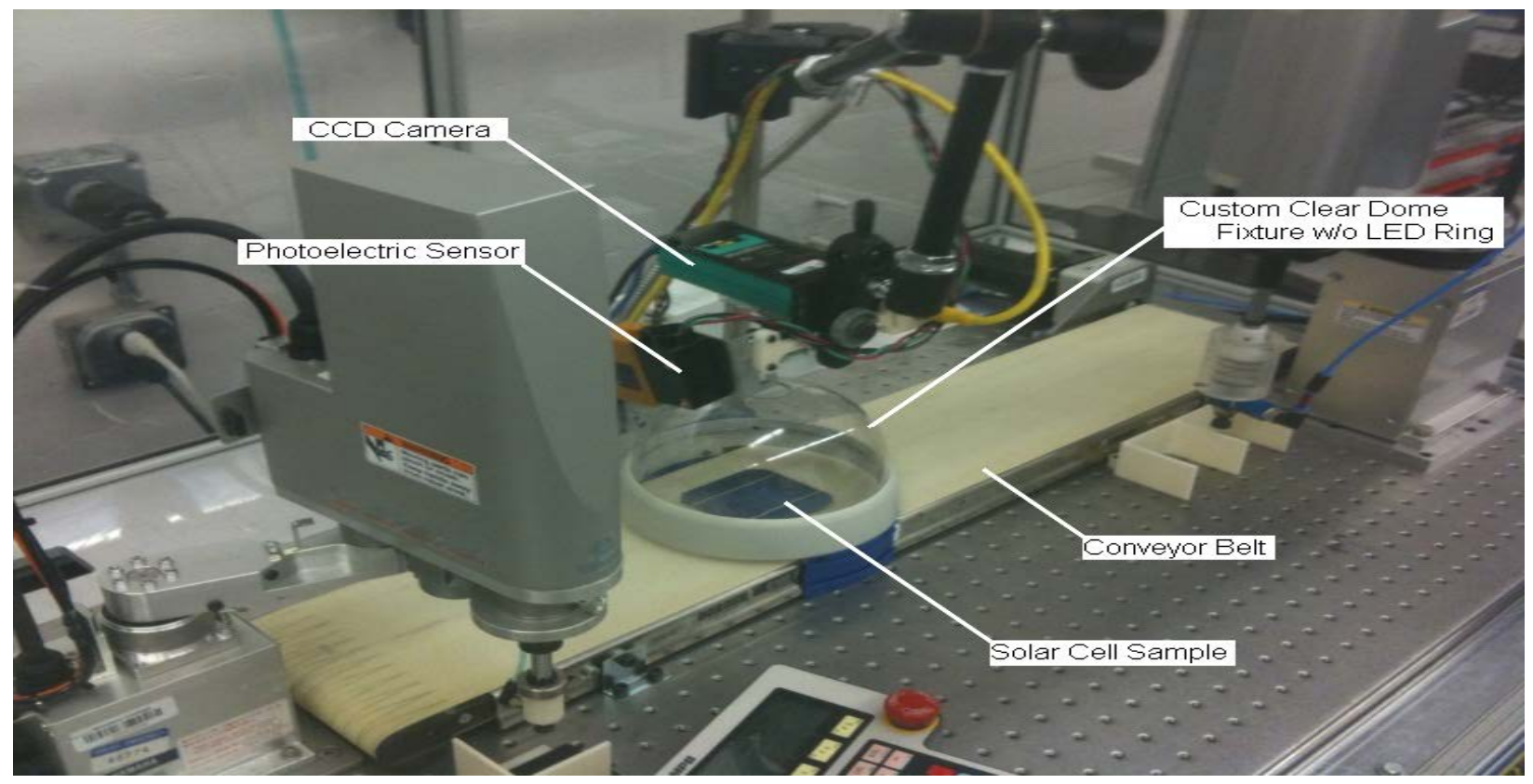

Figure 11: Incorporation of image capture on a conveyer belt system. 


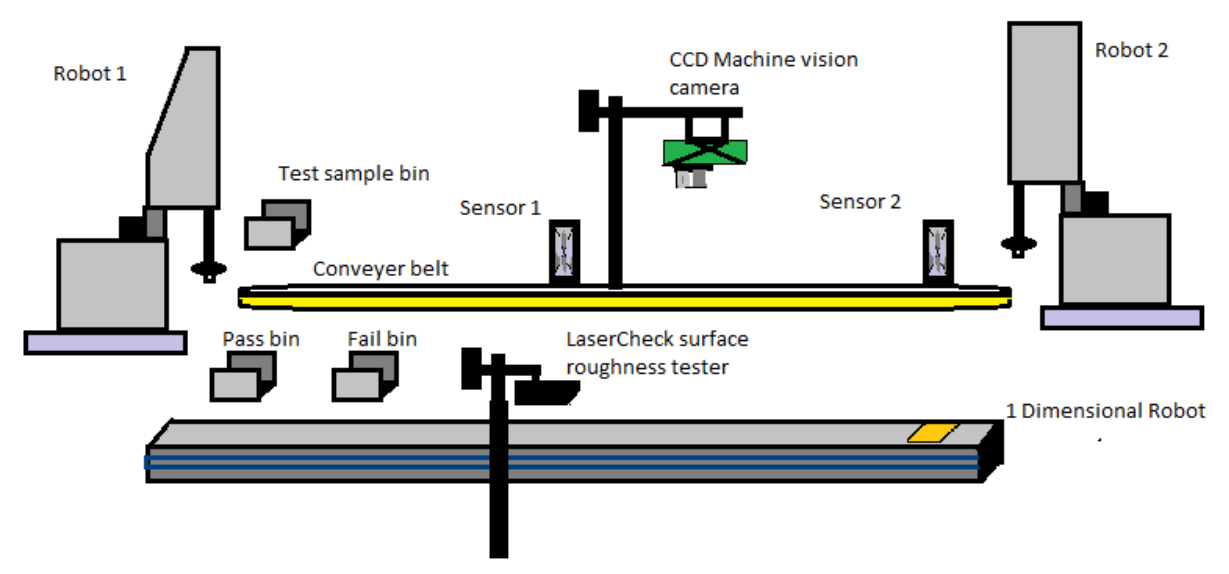

Figure 12: Schematic of conveyer belt solar cell imaging system.

\section{Laser Scanning (Light-Beam Induced Current Imaging)}

Light-beam induced current (LBIC) measurements are a useful diagnostic for analysis of solar cells. A light beam is scanned over the surface of the solar cell, and the photogenerated solar cell current is measured at each light beam position $(x, y)$ on the front surface of the solar cell. A map of current generation versus position is thus produced. This localized solar cell current is a good indicator of defective regions (which produce reduced or no current) and general areal variation of material quality. Also, in multicrystalline solar cells, the grain boundaries are generally areas of diminished photocurrent generation and the reduction in solar cell performance due to grain boundaries can be assessed. Some types of grain boundaries are more detrimental to performance than others (often due to coupling with impurity effects as impurities tend to agglomerate at grain boundaries), and further, many solar cell manufacturing processes utilize grain boundary passivation techniques to varying degrees of effectiveness.

LBIC systems are relatively expensive and complicated. We implemented a simpler system by using a robotic arm to move a laser pointer in order scan the solar cell with a beam of collimated or focused beam of light (Figure 13). Simultaneously, an ammeter measures the solar cell current. Red, green, and blue lasers and comparison of their data can be used for more detailed analysis. The penetration of light into the solar cell depends on wavelength: blue light excites photocarriers near the top surface, and red light throughout the volume of the solar cell. Some scans of solar current vs. position of the laser are shown in Figure 14. As a senior design project, students designed and fabricated a low-cost laser scanner (Figure 15) using parts from a compact optical CD player and G-code software for CNC. 


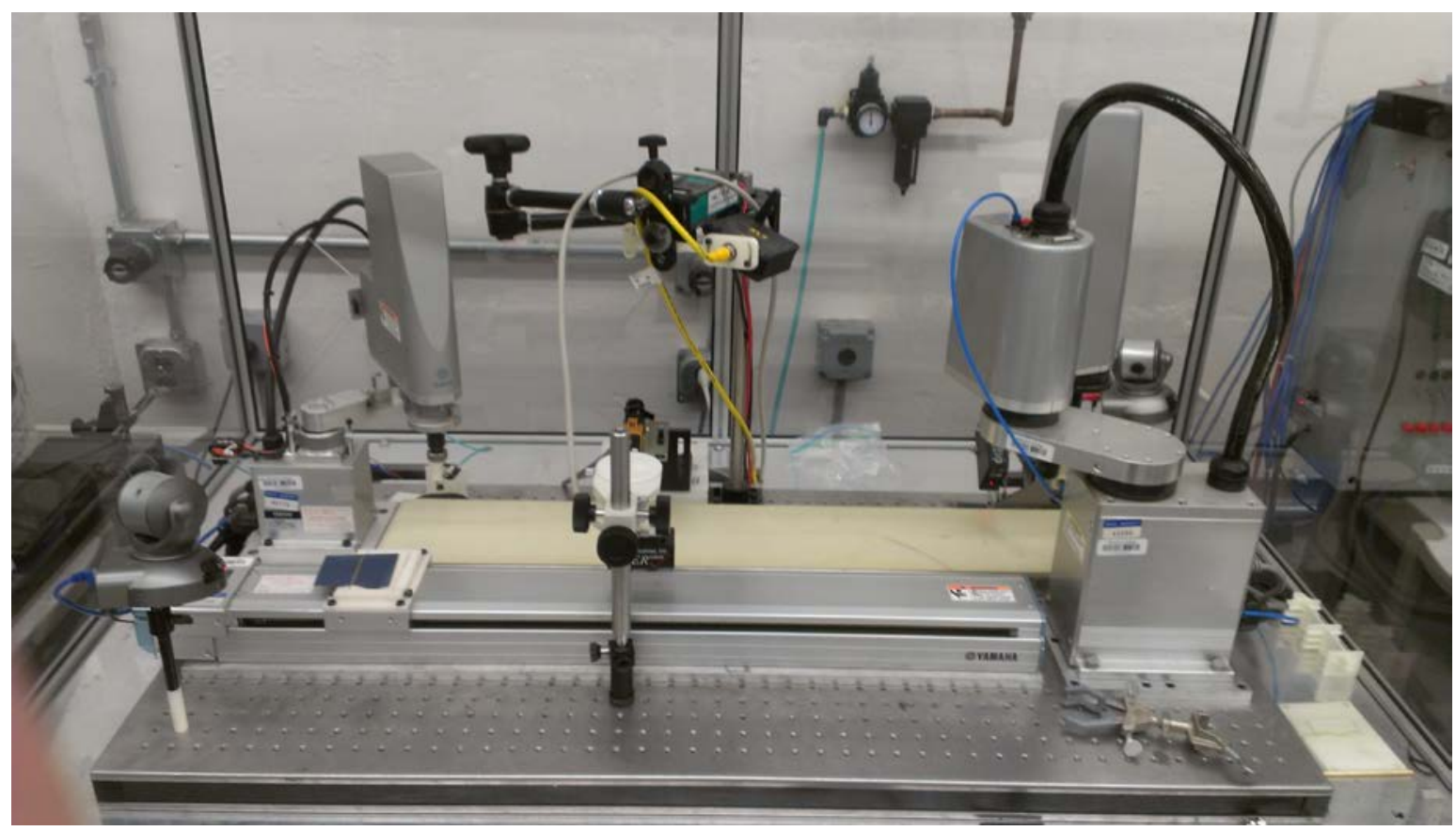

Figure 13: Robotic arm manipulating laser pointer for LBIC measurements that map localized solar cell photocurrent to position on the surface of the solar cell.
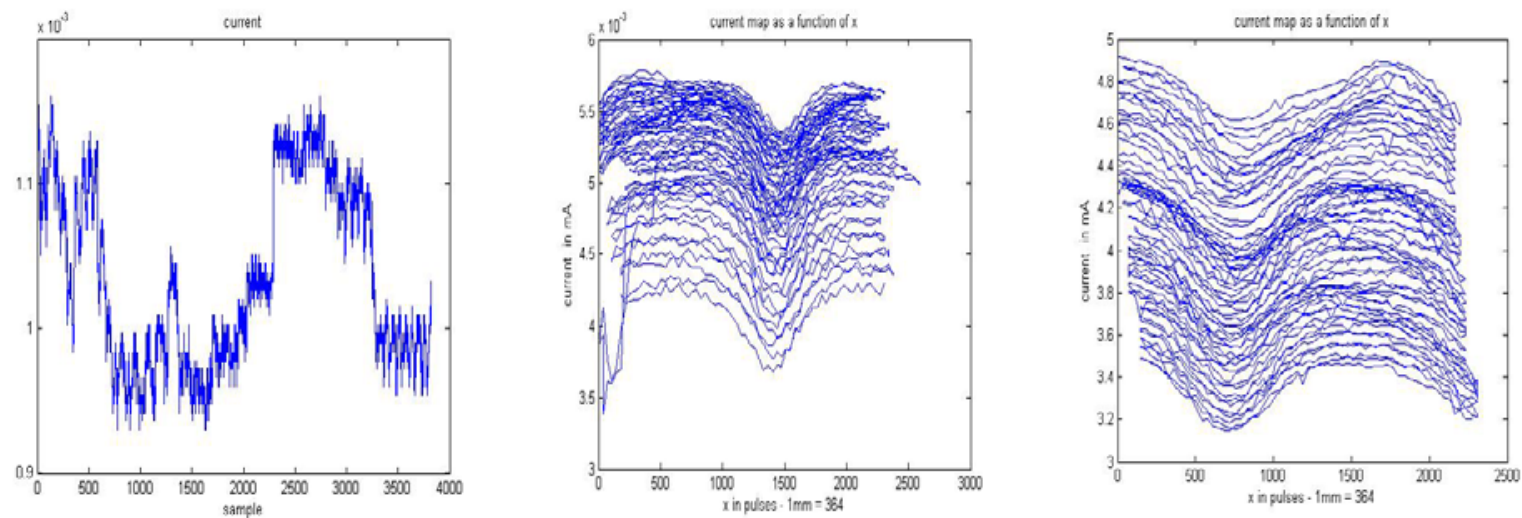

Figure 14: One-dimensional scans of solar cell (LBIC vs. position). 


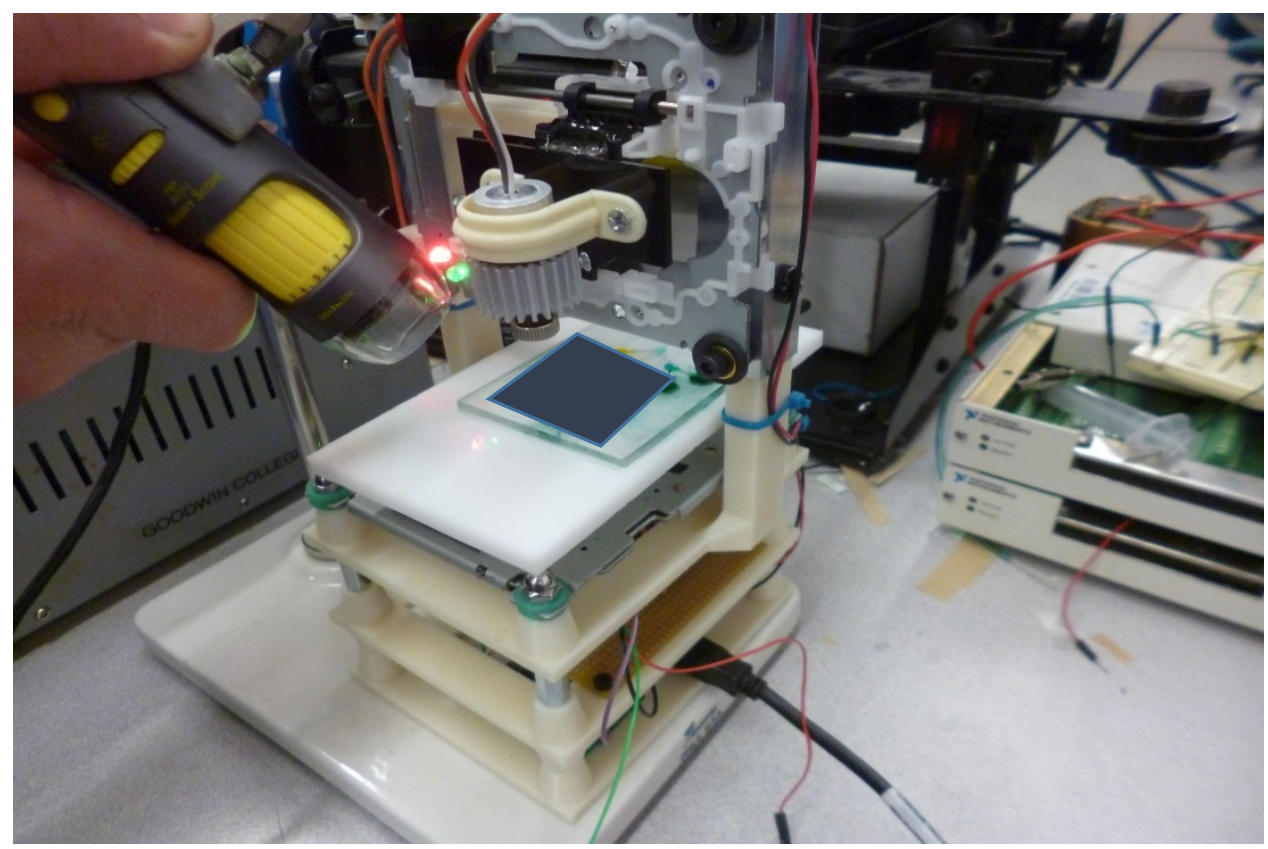

Figure 15: Student project for laser scanning solar cells.

\section{Conclusion and Discussion}

Solar cells and solar cell materials (e.g., multicrystalline silicon wafers) provide excellent vehicles for teaching image capture, processing, and analysis for materials and device characterization and quality control. Solar cells images, captured by simple CCD cameras in LED lighting, are rich in data that students can harvest using basic image analysis techniques provided by software such as MATLAB or ImageJ.

\section{Acknowledgements}

This work was supported by "Solar Cell Imaging: A Gateway for Visualization and Learning in STEM Disciplines” NSF TUES Award DUE-1245872 (June 2013 to May 2015).

\section{Bibliography}

1. J. Haunschild, M. GlatthaAR, M. Demant, J. Nievendick, M. MotzKo, S. Rein, and E.R. Weber, "Quality control of as-cut multicrystalline silicon wafers using photoluminescence imaging for solar cell production” Solar Energy Materials and Solar Cells 94, 12 2007-2012 (2010).

2. Michael G. MAUK, "Image Processing for Solar Cell Analysis, Diagnostics and Quality Assurance Inspection” Ch 14 in Handbook of Research on Solar Energy Systems and Technologies, SOHAIL ANWAR, HARRY EFSTATHIAdis, and SALAhUdDIN QAZI, eds. (IGI Global Publishers, Hershey, Pennsylvania, 2012) pp. 338-375.

3. T. TRUPKE and W. MCMILlan, "Photovoltaics: Photoluminescence imaging speeds solar cell inspection Laser Focus World 12, 6 (Dec 2010).

4. E.C. Quintana, M.A. Quintana, K.D. Rolfe, K.R. Thompson, and P. HaCKe, "Exploring diagnostic capabilities for application to new photovoltaic technologies” Proc. $200934^{\text {th }}$ IEEE Photovoltaic Specialists Conf. 002031-6. 